Teologia i Moralność, volumen 12(2017), numer 2(22)

doi: 10.14746/tim.2017.22.2.18

IGNACY BOKWA

Uniwersytet Kardynała Stefana Wyszyńskiego w Warszawie

Wydział Teologiczny

\title{
Die Stellung und Rolle der Offenbarung Gottes im interreligiösen Dialog
}

Die aktuelle Migrationskrise in Europa wirft wichtige und brennende Fragen nicht nur für Politik und Wirtschaft auf, sondern auch für die Kirche und ihre Theologie. Es geht dabei nicht nur um praktische Lösungsvorschläge, sondern um eine tiefgreifende Reflexion, die die Grundlagen der christlichen Religion betrifft, besonders in ihrem Verhältnis zu den Weltreligionen. In diesem Kontext bekommt die Feststellung, die Offenbarung Gottes sei das Prinzip der gesamten Theologie und der Bestimmung des Verhältnisses des Christentums zu den Weltreligionen und sonstigen Religionen eine neue Bedeutung und ein neues Gewicht. Es braucht wirklich eine vertiefte Reflexion über bestimmte Aspekte der Offenbarung in der christlichen/katholischen Religion sowie über die Rolle und Stellung der Offenbarung Gottes in der Positionsbestimmung des Christentums gegenüber der anderen Religionen (1) und der anderen Religionen untereinander (2), damit es einige Richtlinien für den christlich-islamischen Dialog ausgearbeitet werden können, mit einer speziellen Berücksichtigung der Kompetenzen für einen interreligiösen Dialog (3).

\section{Die Offenbarung Gottes und die nichtchristlichen Religionen}

„Der Offenbarungsbegriff ist in gewisser Weise der Schlüsselbegriff gegenwärtiger Theologie". Diese These hat der deutsche evangelische Theologe, Wolfhart Pannenberg, in seinem Werk unter dem Titel „Offenbarung als

${ }^{1}$ S. Wiedenhofer, Offenbarung, in: Neues Handbuch theologischer Grundbegriffe, erw. Neuausgabe, P. Eicher (Hrsg.), Bd. IV, München 1991, S. 98. 
Geschichte"2 einmalig untermauert und geschildert. Der Duktus dieses wichtigen Buches zeigt auf, wie sich in der Theologie des XX. Jahrhunderts ein Begriff der göttlichen Offenbarung entwickelt hat, der sie als einmalige und totale Selbstmitteilung Gottes in Jesus von Nazareth verstanden hat. Um sich ein Bild von der Bedeutung dieses Schlüsselbegriffs zu machen, kann man die Ausführungen von Peter Eicher zitieren. Der Begriff der Offenbarung erfüllt verschiedene Funktionen im Rahmen der Theologie. Sie fungiert als [1] Qualifikator, insofern als „Offenbarung” zum Synonym für den Inhalt des christlichen Glaubens geworden war. Das zeigt sich anhand von solchen Ausdrücken wie z.B. „die Offenbarung sagt, lehrt...”; [2] als Legitimator, insofern als „Offenbarung” den Geltungsgrund des christlichen Glaubens bildet („Gott hat geoffenbart, dass...); [3] als eine apologetische Kategorie, insofern als "Offenbarung" der entscheidende Grund des christlichen Glaubens ist; [4] als systembildender Funktor, insofern als „Offenbarung” zur fundamentalen hermeneutischen Regel für Verkündigung, Lehramt und Theologie, zum Strukturierungsprinzip der Kirche und zum Einigungsgrund des Glaubens geworden ist $^{3}$.

Katholische Theologie wird nicht müde, auch unter einem scharfen Beschuss der Kritik, die Einmaligkeit und einen besonderen Charakter der christlichen Offenbarung zu betonen und zu verteidigen. Christliche Religion hat in ihrem Ursprung die Präsenz anderer Religionen wahrgenommen, und trotzdem ihren einmaligen, transzendenten Charakter betont ${ }^{4}$. In der historischen Entwicklung der Theologie hat es die Gestalt eines ,außerordentlichen Charakters" der christlichen Offenbarung, dann eines ,,absoluten Anspruchs des Christentums" (G.W.F. Hegel) angenommen ${ }^{5}$. Es gibt eine theologische Begründung dieses Tatbestandes: „Der besondere Charakter des Christentums resultiert vor allem aus der Fülle der göttlichen Offenbarung und des Heils in Jesus Christus. In der Menschwerdung seines Sohnes trat Gott in die Geschichte ein. Jesus Christus als Gott-Mensch hat in höchster Weise Gott geoffenbart. Es darf also keine vollendetere und völlere Offenbarung geben als die, die sich in der Person des Sohnes Gottes verwirklicht hat. Es ist also eine definitive und

${ }^{2}$ Vgl. W. Pannenberg (Hg.), in Verbindung mit R. Rendtorff, U. Wilckens, T. Rendtorff, Offenbarung als Geschichte, Göttingen 1982.

${ }^{3}$ Vgl. P. Eicher, Offenbarung - Prinzip neuzeitlicher Theologie, München 1977, S. 48-57.

${ }^{4}$ Vgl. M. Żmudziński, Wyjątkowy charakter Objawienia chrześsijańskiego $w$ kontekśsie pluralizmu religijnego, „Studia Elbląskie” XI (2010) S. 113; C. Böttigheimer, Lehrbuch der Fundamentaltheologie. Die Rationalität der Gottes-, Offenbarungs- und Kirchenfrage, Freiburg-BaselWien 2009, S. 357: „So wurde stets die Überzeugung bewahrt, dass sich das Christentum einem transzendentalen Ursprung verdanke und Religion göttlichen Ursprungs sei”.

${ }^{5}$ Vgl. I.S. Ledwoń, Wyjątkowy charakter chrześcijaństwa, in: Chrześcijaństwo a religie. Dokument Międzynarodowej Komisji Teologicznej. Tekst - Komentarze - Studia, I.S. Ledwoń, K. Pek (Hg.), Lublin-Warszawa 1999, S. 81. 
völlig übernatürliche sowie heilshafte Offenbarung. Entscheidend -auch qualitativ - übertrifft sie die Offenbarung durch die Schöpfung, Propheten, Charismatiker und andere Gesandte Gottes oder die, die auf einem rein inneren Weg

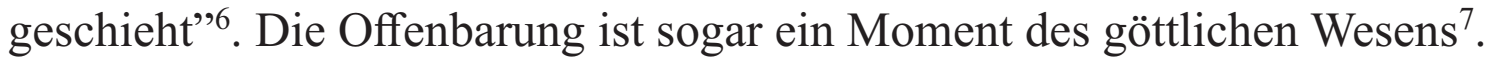

Die sonderbare Stellung der Offenbarung, von der katholischen Theologie stets betont und begründet ${ }^{8}$, ist das Kriterium für die Bestimmung des Verhältnisses zwischen Offenbarung und Religion ${ }^{9}$. Katholische Sicht dieses Problems spricht sogar von der göttlichen Offenbarung als Grund der Religion. Eine solche Fragestellung gehört zu den schwierigeren in der heutigen Theologie der Religion. Es beinhaltet nämlich den ursprünglichen Anspruch des Christentums, die einzig wahre und heilshafte, weil geoffenbarte Religion zu sein. Eine breitere Sicht dieses Problems bedeutet die Frage nach der Präsenz der soteriologischen Werte in den nichtchristlichen Religionen ${ }^{10}$. Dazu ist festzustellen, dass aus theologischer Sicht nicht alle Religionen als Offenbarungsreligionen zu bezeichnen sind: „Es ist nämlich darauf zu achten, ob der zugrunde liegende Offenbarungsbegriff für eine bestimmte Transzendenzerfahrung steht, die in irgendeiner Form in allen Religionen vorkommt, und inwiefern diese eine Selbstoffenbarung Gottes, mit der sich eine bestimmte Heilswegskonzeption verbindet" . Die Antworten auf eine Frage nach der Präsenz der soteriologischen Werte in den nichtchristlichen Religionen sind in drei Gruppen aufgeteilt. Sie sind Resultat der verschiedenen Antworten auf die Frage, ob ein Nichtchrist zum ewigen Heil gelangen kann. Relativ schnell haben sich zwei Pole gebildet. Die einen bezogen sich auf die Formel vom hl. Cyprian: Extra Ecclesiam salus nulla. Laut eine Überinterpretation dieses Theologoumenons hatten die Nichtchristen keine Heilschance, solange sie nicht getauft werden. Diese Position ist also als ein Ekklesiozentrismus und somit ein soteriologi-

${ }^{6}$ M. Rusecki, Objawienie Boże podstawa religii, in: Teologia religii. Chrześcijański punkt widzenia, G. Dziewulski (Hg.), Łódź-Kraków 2007, S. 166.

${ }^{7}$ Vgl. R. Leuze, Das Christentum. Grundriss einer monotheistischen Religion, Göttingen 2010, S. 28-39.

${ }^{8}$ Vgl. z.B. L. Scheffczyk, Absolutny charakter chrześcijaństwa, in: Tajemnica odkupienia, L. Balter u.a. (Hg.), Poznań 1997, S. 477-490; I.S. Ledwoń, Wyjątkowy charakter chrześcijaństwa, in: Chrześcijaństwo a religie. Dokument Międzynarodowej Komisji Teologicznej. Tekst-komentarze - studia, S. 80-100; H. Waldenfels, Chrystus a religie, übers. von B. Drąg, Kraków 2004, S. 10-26; M. Żmudziński, Wyjątkowy charakter objawienia chrześcijańskiego w kontekście pluralizmu religijnego, „Studia Elbląskie” 11 (2010) s. 113-122.

${ }_{9}$ Vgl. M. Rusecki, Objawienie Boże podstawa religii, in: Teologia religii. Chrześcijański punkt widzenia, S. 157-182.

${ }^{10}$ Vgl. U. Pękala, Eine Offenbarung - viele Religionen. Die Vielfalt der Religionen aus christlicher Perspektive auf der Grundlage des Offenbarungsbegriffs Wolfhart Pannenbergs, Würzburg 2010, S. 133-141.

${ }^{11}$ C. Böttigheimer, Lehrbuch der Fundamentaltheologie. Die Rationalität der Gottes-, Offenbarungs- und Kirchenfrage, Freiburg-Basel-Wien 2009, S. 357. 
scher Exklusivismus zu bezeichenen. Die anderen hielten eine Option offen, die Nichtchristen können im Rahmen ihrer eigenen Religion das Heil erfahren. Es geschieht im Zusammenhang mit der Gnade Christi (Christozentrismus, soteriologischer Inklusivismus). Heutzutage wird eine dritte Position vertreten, und zwar eine relativistische. Sie betrachtet das Christentum als heilsmäßig gleichwertig mit den anderen Religionen, die als außerordentliche Heilswege bezeichnet werden (Theozentrismus, soteriologischer Egalitarismus). Diese drei Paradigmen sind in der Tat drei verschiedene Modelle der Relation des Christentums zu den Religionen. Sie entspringen der Art und Weise, wie die zwei fundamentalen Grunddogmen harmonisiert werden: die Einzigartigkeit der Heilsvermittlung Jesu Christi und seiner Notwendigkeit zum Heil (Apg 4, 12) mit dem allgemeinen Heilswillen Gottes (1 Tim 2, 3-5 $)^{12}$.

Katholische Theologie, schon zur Zeit des Zweiten Vatikanischen Konzils und auch nach ihm, identifiziert sich am meisten mit der inklusivistischen Position. Bezeichnend ist, dass das erste Mal in der ganzen Kirchengeschichte ein Konzil die Stellung zu den nichtchristlichen Religionen genommen hat. Es gibt viele Aussagen der Konzilsväter, die die Möglichkeit des Heils durch die nichtchristlichen Religionen betonen, die Elemente der Wahrheit in ihnen unterstreichen, als Frucht der Wirkung des Heiligen Geistes. Die dogmatische Konstitution über die Kirche „Lumen gentium” spricht von der Fülle des Heils, die ausschließlich in der Kirche Jesu Christi erreichbar ist. Das Heilswerk Jesu Christi hat eine universelle Bedeutung. In ihm, dem fleischgewordenen Gottessohn, ist die Fülle der göttlichen Offenbarung erfahrbar. So ist das Christentum eine Offenbarungsreligion ${ }^{13}$ und hat mit der Gründer-Gestalt, Jesus dem Christus grundsätzlich zu tun ${ }^{14}$.

In den nachkonziliären Aussagen des kirchlichen Lehramtes gibt es nur wenige Stellen, an denen das Problem des Heils in den nichtchristlichen Religionen behandelt wird ${ }^{15}$. Relativ oft wird der Text vom Missions-Dokument „Ad gentes" reflektiert, der die Religionen als Ausdruck der menschlichen Suche nach Gott versteht. Das kann zu einem falschen Schluss führen, die nichtchristlichen Religionen würden ein Menschenwerk ${ }^{16}$. Das Christentum,

${ }^{12}$ Vgl. G. Dziewulski, Objawienie jako kryterium określenia relacji chrześcijaństwa do religii, „Łódzkie Studia Teologiczne” 15 (2006) S. 41-42; M. Rusecki, Objawienie Boże podstawa religii, in: Teologia religii. Chrześcijański punkt widzenia, S. 167-173.

${ }^{13}$ Vgl. C. Böttigheimer, Lehrbuch der Fundamentaltheologie. Die Rationalität der Gottes-, Offenbarungs- und Kirchenfrage, S. 357-362.

${ }^{14}$ Vgl. H. Waldenfels, Christus und die Religionen, Regensburg 2002, S. 11-26.

${ }^{15} \mathrm{Vgl}$. M. Rusecki, Elementy zbawcze w religiach pozachrześcijańskich, in: Religia w świecie wspótczesnym, H. Zimoń (Hg.), Lublin 2001, S. 531-562.

${ }^{16}$ Vgl. das Missionsdekret Ad gentes, N. 3: „Dieser umfassende Plan Gottes für das Heil des Menschengeschlechtes wird nicht allein auf eine gleichsam in der Innerlichkeit des Menschen verborgene Weise verwirklicht, ebenso nicht bloß durch Bemühungen, auch religiöser Art, mit 
im Gegenteil zu den Religionen, sollte eine Religion sein, in der Gott nach dem Menschen sucht. Es gibt Gründe für die These, dass die nachkonziliären Aussagen des kirchlichen Lehramtes die Intuitionen des Vaticanum II. entwikkelt und vertieft haben. Andere sprechen dafür von einem Regress. Die Religionen werden zwar als Wirkungsort des Heiligen Geistes dargestellt, jedoch das göttliche Heil wird kaum definiert. Diese Wege sollen nur Gott bekannt sein. Die nachkonziliären Dokumente des kirchlichen Lehramtes zeigen auch kaum den Zusammenhang zwischen den nichtchristlichen Religionen und der Offenbarung Gottes. Selbst die Konstitution Dei Verbum weist auf verschiedene Offenbarungsaktivitäten Gottes in der Welt, vor allem in der Schöpfung und durch die Schöpfung. Die biblischen Texte interpretieren diese Taten Gottes als Wirkung von einer universellen Bedeutung. Dazu noch in den nichtchristlichen Religionen gibt es ein sehr lebhaftes Bewusstsein, in ihnen seien Elemente der Offenbarung Gottes beinhaltet ${ }^{17}$.

Offenbarung und Heil bilden eine untrennbare Einheit. Gott offenbart sich nicht, um den menschlichen Wissensstand zu bereichern, sondern um die Menschheit sowie den gesamten Kosmos zu retten. Die Entstehung der Religion ist somit in der Offenbarung begründet ${ }^{18}$. Die Herkunft der Religion ist mit Hilfe der Religionswissenschaften nicht erklärbar. Das kann nur die Theologie der Religion leisten. Sie zeigt die Religion als Resultat der Offenbarungsinitiative Gottes. Die heutige Theologie zeigt die Offenbarung als eine Art Einladung und unverdiente Gabe. Karl Rahner betonte den allgemeinen Heilswillen Gottes (Jesus Christus als Heilbringer), bezogen auf die menschliche Freiheit. Diese zwei Tatsachen verlangen nach einem universalen, offenbarenden Wirken Gottes, weit über die Grenzen des Alten und Neuen Testaments, zugänglich für die Menschen aller Zeiten und Kulturen: „Die universale Heilsgeschichte ist zugleich Offenbarungsgeschichte"19. Erst diese theologische Feststellung erschließt den Zugang zum rechten Begriff der revelatio naturae, mit einem starken biblischen Hintergrund. Im Laufe der Zeit wurde aus

denen die Menschen Gott auf vielfältige Weise suchen, ,ob sie ihn vielleicht berühren oder finden möchten, wiewohl er nicht ferne ist von einem jeden von uns' (vgl. Apg 17,27). Diese Bemühungen bedürfen nämlich der Erleuchtung und Heilung, wenn sie auch aufgrund des gnädigen Ratschlusses des vorsorgenden Gottes zuweilen als Hinführung zum wahren Gott oder als Bereitung für das Evangelium gelten können".

${ }_{17} \mathrm{Vgl}$. M. Rusecki, Elementy zbawcze $w$ religiach pozachrześcijańskich, in: Odkupienie a dialog międzyreligijny. Materiaty z sympozjum w Obrze 20-21 kwietnia 1999 roku, W. Kluj (Hg.), Poznań 1999, S. 41-48.

${ }^{18}$ Vgl. T. Jähnichen, A. Witte-Karp, Religion und Offenbarung. Ein Studienbuch zur Einführung in die Systematische Theologie, 2. überarb. Aufl., Waltrop 2007, S. 323-456.

${ }^{19}$ Vgl. K. Rahner, Grundkurs des Glaubens. Einführung in den Begriff des Christentums, Freiburg-Basel-Wien 1984, S. 149-151: „Die universale Heilsgeschichte ist zugleich Offenbarungsgeschichte”. Vgl. dazu: Universale Offenbarung? Der eine Gott und die vielen Religionen, W. Zager (Hg.), Leipzig 2013. 
diesem theologischen Argument eine philosophische quaestio diaputata, betrachtet als eine rein rationale, philosophische, ohne Bezug auf jegliche Gnade Erkenntnis, bekannt unter dem Namen von der „natürlichen Offenbarung”. Somit wurden die nichtchristlichen Religionen, in denen diese theologische Perspektive eine wesentliche Rolle spielte, zu den „natürlichen Religionen” erklärt. Da der Mensch eine angeborene Offenheit auf die Transzendenz aufweist, kann man an dieser Stelle eher von einem „Zeugnis der Schöpfung” reden. Die Erkenntnis Gottes auf dem Wege der Schöpfung ist eine religiöse, personale und symbolische Erkenntnis Gottes, und nicht eine philosophische, indem sie zu einer existentiellen Erfahrung mit Gott führt. Der Mensch ist eine Epiphanie Gottes, als Gottes Ebenbild und Krone der Schöpfung. Da der Sohn Gottes an der Schöpfung beteiligt ist ${ }^{20}$, trägt die Schöpfung christische Züge und die Welt ist das erste, universale Zeichen der göttlichen Offenbarung ${ }^{21}$.

\section{Die Offenbarung Gottes und die Religionen untereinander}

Die Offenbarung ist nicht nur das Kriterium für die Bestimmung des Verhältnisses zwischen dem Christentum und den nichtchristlichen Religionen, sondern auch der Relationen zwischen den nichtchristlichen Religionen selber $^{22}$. Die oben ausgeführten Reflexionen haben gezeigt, dass die göttliche Offenbarung ein Kriterium für die Bestimmung des Verhältnisses zwischen dem Christentum und den nichtchristlichen Religionen bildet. Die Aufgabe der Theologie der Religion besteht unter anderen darin, von der rein rationalen und philosophischen Sicht der Uroffenbarung Gottes in und durch die Schöpfung wegzuschauen und eine theologische Fassung dieses Problems wieder einzuführen. Das wird ein neues Licht auf die Frage nach der Entstehung der nichtchristlichen Religionen werfen. Die christliche Theologie der Religion, die auf dem trinitarisch-christologischen und ekklesiologischen Fundament baut ${ }^{23}$, versteht den tiefsten Sinn jeder Religion als eine übernatürliche existentielle Bindung zwischen dem auf die Transzendenz ausgerichteten Menschen und dem sich ihm in der Offenbarung nähernden Gott. Ohne weiteres ist diese Feststellung ein wichtiges Kriterium, in dem die Offenbarung eine entscheidende Rolle spielt, da Gott diese übernatürliche Bindung mit dem Menschen festlegt.

${ }^{20} \mathrm{Vgl}$. Kol 1, 15-17.

${ }^{21}$ Vgl. M. Rusecki, Objawienie Boże podstawa religii, in: Teologia religii. Chrześcijański punkt widzenia, S. 177-182: „Objawieniowa geneza religii a zbawienie”; G. Dziewulski, Objawienie jako kryterium określenia relacji chrześcijaństwa do religii, S. 54-56.

22 Vgl. G. Dziewulski, Objawienie jako kryterium określenia relacji między religiami, „Seminare” 24 (2007) S. 127-143.

${ }^{23}$ Vgl. I.S. Ledwoń, Wyjątkowy charakter chrześcijaństwa, S. 518-525. 
Dieses Kriterium soll mit den Angaben der klassischen Philosophie der Religion sowie der Religionswissenschaften harmonisiert werden. Die Theologie der Religion befasst sich so mit der Vertiefung der gegenseitigen Verhältnisse zwischen Offenbarung, Heil und Religion. Das entscheidende Element der Religion ist das Heil. Ohne den Bezug auf das Heil darf es keine Religion geben. Dabei ist festzustellen, dass nicht die Religionen als solche bewirken das Heil, sondern die Offenbarung Gottes, die Frucht der Wirkung des Heiligen Geistes ${ }^{24}$. Die Religion hat also einen übernatürlichen Ursprung in Gott und seiner Offenbarung. Dazu kommt die Bereitschaft des Menschen, sich auf Gott hin zu öffnen und mit der Gnade Gottes mitzuarbeiten. Es schließt die Gefahr einer anthropologischen Reduktion aus. Das Wesen der Religion darf auch auf ihre soteriologische Effektivität nicht reduziert werden. Diese Aussage ist wiederum im Kontext der pluralistischen Religionstheologie wichtig ${ }^{25}$. Es würde nämlich die zentrale Rolle der Offenbarung Gottes in der Religion wesentlich schwächen. Somit werden alle naturalistische (und dadurch reduktionistische) Erklärungen der Genese der Religion als nicht ausreichend und fehlerhaft klar abgelehnt ${ }^{26}$. Die menschlichen Möglichkeiten, Gott mit nur der Kraft der ratio erkennen zu können, enden relativ schnell mit einem Postulat, die Erste Ursache als eine Möglichkeit zuzulassen. Dieser Feststellung folgen dann die Erfüllung in ihr existentieller Erwartungen des Menschen, wie eine Relation zu einer anderen Person, Erkenntnis einer vollen Wahrheit oder eine richtige Verwirklichung der Freiheit ${ }^{27}$. Der auf seine natürlichen Begabungen angewiesene Mensch erfährt aber relativ schnell, dass es unmöglich ist, eine

24 Vgl. Johannes Paul II, Enzyklika Redemptoris missio, Nr. 28-29: „Der Geist zeigt sich in besonderer Weise in der Kirche und in ihren Mitgliedern; jedoch ist seine Gegenwart und sein Handeln allumfassend, ohne Begrenzung durch Raum und Zeit. Das Zweite Vatikanische Konzil erinnert an das Wirken des Geistes im Herzen jedes Menschen, durch »die Samen des Wortes «, auch durch religiöse Anregungen, durch Anstrengungen allen menschlichen Handelns, sofern es auf die Wahrheit, auf das Gute, auf Gott ausgerichtet ist. Der Geist gibt dem Menschen »Licht und Kraft, um auf seine höchste Berufung zu antworten«; durch den Geist »kann der Mensch im Glauben zum Betrachten und Verkosten des Geheimnisses des Göttlichen Heilsplanes gelangen«; überdies »müssen wir annehmen, daß der Heilige Geist allen die Möglichkeit bietet, mit dem Ostergeheimnis in Berührung zu kommen in einer Weise, die nur Gott kennt«; in jedem Fall weiß die Kirche, »daß der Mensch, vom Geist Gottes angespornt, vom Problem der Religion nicht völlig unberührt bleiben« und »daß er immer den Wunsch haben wird, wenigstens in Umrissen zu erkennen, was der Sinn seines Lebens, seines Tuns, seines Todes sei«. Der Geist steht also am Ursprung der Existenz und Glaubensfrage jedes Menschen, die sich ihm nicht nur in bestimmten Situationen, sondern aus der Struktur seines Daseins selbst stellt" (N. 28).

${ }^{25}$ Vgl. Sung Ryul Kim, Gott in und über den Religionen. Auseinandersetzung mit der ,pluralistischen Religionstheologie" und das Problem des Synkretismus, Zürich 2010, S. 133-167.

${ }^{26}$ Vgl. G. Dziewulski, Objawienie jako kryterium określenia relacji między religiami, S. 140.

27 Vgl. H.-J. Höhn, Postsäkular. Gesellschaft im Umbruch - Religion im Wandel, Paderborn-München-Wien-Zürich 2007, S. 59-63. 
übernatürliche Relation, also Glauben, mit Gott aufzubauen. Gott allein vermag es nämlich.

Christliche Theologie der Religion steht und fällt mit der Überzeugung, am Ursprung der Religion stünde Gott und seine Offenbarung. Die übernatürliche Antwort des Menschen auf die Offenbarung nimmt die Gestalt des Glaubens an. Zwar im verschiedenen Grad, aber wesentlich verwirklichen alle drei Religionen: Judaismus, Christentum und Islam einen Bezug auf die historische Offenbarung Gottes. Die anderen Religionen realisieren ihre Bezogenheit auf die Offenbarung durch die Erkenntnis Gottes in der Schöpfung und durch sie. Im jeden Menschen wirkt von Anfang an die prophetische sowie transzendentale Offenbarung Gottes. Der Mensch ist fähig, mit der Offenbarung rational umzugehen. Deswegen kann er die Welt als Gottes Werk erkennen und diese Welt gestalten. Er erfährt in sich die Stimme Gottes als Gewissen, sucht nach einem unvergänglichen Glück, nach einer Selbstverwirklichung sowie Gerechtigkeit ${ }^{28}$. Diese Erfahrungen sind als Epiphanien Gottes einzustufen. An dieser Stelle kommen zu Sprache die Analogien sowie Unterschiede zwischen den Religionen. Sie entspringen den unterschiedlich Möglichkeiten, die Offenbarung Gottes erreichen zu können, sie korrekt zu entziffern. Dieser Vorgang ist wichtig, da die Religionen mit dem Heil immer zu tun haben sollen. Falsch wäre jedoch die Meinung, sie wären alle gleichwertig oder von gleicher soteriologischer Wirkung. Das II Vatikanische Konzil ist sich dessen bewusst, dass die nichtchristlichen Religionen einige Fehler in sich haben, die die Grundwahrheiten von Gott, Mensch und Welt betreffen. Trotz der Offenheit auf den Dialog und Austausch mit den nichtchristlichen Religionen darf das Christentum auf seine Grundüberzeugung nicht verzichten: In Jesus Christus ist die Fülle der Offenbarung Gottes gekommen. Diese Fülle lässt sich nicht übertreffen. Die Bestimmung des Verhältnisses des Christentums zu den anderen Religionen sowie der nichtchristlichen Religionen untereinander soll diese Grundüberzeugung wahrnehmen. Ohne sie wäre der interreligiöse Dialog nicht echt, schädlich und falsch. Aus diesem Grund steht das Christentum zu der Überzeugung, in den nichtchristlichen Religionen seien manche Elemente der Offenbarung (bzw. „Erleuchtungen”) beinhaltet als Bruchteile der Heiligung und Wahrheit. Nur die kanonischen Texte der Heiligen Schrift gelten als von Gott inspiriert. Daher kommt auch die Hypothese einer an die Offenbarung geknüpften Genese der Religion. Jede konkrete Religion entstand unter verschiedensten und kompliziertesten Bedingungen, was die Vielfalt der Religionen erklärt und begründet. All das dient dann als praktisches und adäquates

${ }^{28}$ Katechismus der katholischen Kirche, Nr. 29: „Das Verlangen nach Gott ist dem Menschen ins Herz geschrieben, denn der Mensch ist von Gott und für Gott erschaffen. Gott hört nie auf, ihn an sich zu ziehen. Nur in Gott wird der Mensch die Wahrheit und das Glück finden, wonach er unablässig sucht". 
Kriterium in der religionstheologischen Forschung. Die Offenbarung Gottes ist die zentrale Größe, an der der verschiedene Grad der Präsenz der Offenbarung in der Schöpfung und Geschichte erklärbar wird. Das erklärt auch, warum die Religionen in ungleichem Grad eine universale Bedeutung haben. So ist auch in der heutigen postmodernen Zeit die Frage nach der Wahrheit und soteriologischer Fähigkeit einer Religion zu stellen, nach der Verwandtschaft der Religionen, nach ihren Unterschieden und Ähnlichkeiten.

Im interreligiösen Dialog spielen zwei Fragen eine zentrale Rolle: die Heilsfrage und die Wahrheitsfrage ${ }^{29}$. „Die größere Heilssituation des Christentums bedeutet, Menschen, Kulturen und Religionen verantwortlich, mit Hilfe des Dialogs zur Christusbegegnung zu führen und damit zu ihrer eigenen Erfüllung. Dabei ist all das positiv zu würdigen, was in den anderen Religionen wahr und heilig ist, insofern es nur auf Christus hin transparent ist" 30 . Die Wahrheitsfrage ist im interreligiösen Dialog bitternotwendig ${ }^{31}$. Es darf dabei nicht nur um den Austausch von Informationen und eine friedliche, partnerschaftliche Koexistenz der Religionen gehen: „Theologisch und philosophisch macht der Dialog nur Sinn, wenn die Wahrheitsproblematik nicht ausgeklammert und der Dialog als Instrument gemeinsamer Wahrheitsfindung angesehen und genutzt wird"32. Die Theologie der Religionen hat damit zur Aufgabe, zur Trägerin eines rational verantwortlichen Diskurses zu werden. Einer der wichtigsten Gründe dafür ist die Feststellung, dass sich Wahrheit und Heil gegenseitig bedingen ${ }^{33}$. Ist es so, dann wird jede Beliebigkeit ausgeschlossen: „Religionen sind nicht a priori als gleich wahr und soteriologisch als gleichwertig zu bezeichnen. Wenn dem so wäre, hätten die Heilswege der unterschiedlichen Religionen allesamt pauschal als legitime, d.h. theologisch qualifizierte Heilswege zu gelten und die christliche Mission hätte allein die Aufgabe, [...], die Achtung vor der fremden Religion [zu] vertiefen und keine andere Sorge [zu] haben, als daß der Hindu ein besserer Hindu, der Buddhist ein besserer Buddhist, der Moslem ein besserer Moslem werde'"'34. In diesem Kontext begreift

29 Vgl. F. Senn, Verantwortet glauben. Fundamentaltheologie, Zürich 2016, S. 221-231; C. Böttigheimer, Lehrbuch der Fundamentaltheologie. Die Rationalität der Gottes-, Offenbarungsund Kirchenfrage, S. 504-523.

${ }^{30}$ C. Böttigheimer, Lehrbuch der Fundamentaltheologie. Die Rationalität der Gottes-, Offenbarungs- und Kirchenfrage, S. 513.

${ }^{31}$ Vgl. R. Krauss, Gottes Offenbarung und menschliche Religion. Eine Analyse des Religionsbegriffs in Karl Barths Kirchlicher Dogmatik mit besonderer Berücksichtigung F. D. E. Schleiermachers, The Edwin Mellen Press, Lewiston/Queenston/Lampeter 1992, S. 193-325.

${ }^{32}$ C. Böttigheimer, Lehrbuch der Fundamentaltheologie. Die Rationalität der Gottes-, Offenbarungs- und Kirchenfrage, S. 515-516.

${ }^{33} \mathrm{Vgl}$. K. Ward, Religion and Revelation. A Theology of Revelation in the World's Religions, Oxford 1994, S. 316-317.

${ }^{34}$ C. Böttigheimer, Lehrbuch der Fundamentaltheologie. Die Rationalität der Gottes-, Offenbarungs- und Kirchenfrage, S. 517. 
sich die Kirche als Gemeinschaft der Heilsgegenwart Gottes ${ }^{35}$. Das Christentum ist fest überzeugt: „Maßstab und Kriterium der Wahrheit ist Jesus Christus und die in ihm begegnende Liebe Gottes" ${ }^{36}$. In diesem Geiste ist Frage nach der Begegnung zwischen Christentum und Islam im heutigen Europa anzugehen.

\section{Christentum-Islam: Dialog und Inkulturation - eine Herausforderung für das Christentum in Europa}

Islam als Religion bringt mit sich heutzutage eine der größten Herausforderungen für die Kirche in Europa. Die Migrationskrise im Abendland - besonders in den letzten Jahren - hat dieses Problem mit aller Klarheit neu bewusst gemacht. Trotz aller Schwierigkeiten in den Kontakten zwischen Christentum und Islam soll der Dialog zwischen diesen beiden Religionen weiterhin praktiziert und fortgesetzt werden. Der interreligiöse Dialog als solcher kann aber nur gelingen, wenn beide (oder mehrere) Seiten eine dialogische Fähigkeit aufweisen. Im Falle des christlich-islamischen Dialogs ist diese Bedingung nicht unbedingt selbstverständlich.

Vor allem ist festzustellen, dass die Präsenz des Islam in Europa zu Veränderungen in jenen Ländern führt, in denen die Moslems leben ${ }^{37}$. Von Bedeutung sind hier historische Erfahrungen mit Islam in Europa, angefangen spätestens im VIII Jahrhundert, von der Iberischen Halbinsel über Süditalien bis zum Schwarzen Meer. Der positive Einfluss der islamisch-orientalischen Kultur (Wissenschaft, Landwirtschaft, Handel, Kultur und Kunst) wird meistens verschwiegen, dafür kommen regelmäßig zur Rede negative Erinnerungen an die Kriegskonfrontation mit dem osmanischen Imperium. Dazu ist zu sagen, dass das Klima des christlich-islamischen Dialog unter einem starken Einfluss der Migrationserfahrungen der letzten Jahrzehnte ${ }^{38}$. In der Welt von heute, auch in Europa, nimmt die Angst vor dem islamischen Extremismus stark zu. Dazu kommt ein schwer definierbares Gefühl einer Gefährdung

${ }^{35}$ Vgl. R. Miggelbrink, 50 Jahre nach dem Konzil. Die Zukunft der katholischen Kirche, Paderborn-München-Wien-Zürich 2012, S. 42-46.

${ }^{36}$ C. Böttigheimer, Lehrbuch der Fundamentaltheologie. Die Rationalität der Gottes-, Offenbarungs- und Kirchenfrage, S. 521.

37 Vgl. M. Rohe, Zum Wandel der deutschen und europäischen Gesellschaften durch die Präsenz des Islam, in: Wandel durch Dialog. Gesellschaftliche, politische und theologische Aspekte des Dialogs zwischen Islam und Christentum, H. Engin, M. Reder (Hg.), Stuttgart 2014, S. 14-19.

38 Vgl. E. Sakowicz, Rozwiązywanie konfliktów i budowanie jedności. Pedagogiczna propozycja M. Fethullaha Gülena, in: Dialog chrześcijańsko-muzułmański, t. 3: Teoria - praktykaperspektywy, M. Lewicka, C. Lapisz (Hg.), Toruń 2013, S. 107-124. 
durch alles, was mit der islamischen Kultur und Religion zu tun hat ${ }^{39}$. An dieser Stelle melden sich Folgen einer unüberlegten und unverantwortlichen Migrationspolitik. In Europa werden Migrationen eher als Gefahr und nicht als Chance eingestuft. Dieser und viele andere Faktoren, erschweren den Dialog spürbar. Im öffentlichen Bereich bestimmen diese negativen Prozesse das Bild von Islam. Als Beispiele einer positiven Einstellung zu den moslemischen Gläubigen dienen in Deutschland unter anderen institutionelle Gleichstellung des islamischen Religionsunterrichts in den öffentlichen Schulen sowie der islamischen Konfessionsreligion an manchen Universitäten. Die Änderungen betreffen auch gegenständliche Modifizierung des Gesetzes, Baugenehmigungen für die Moscheen, zum Teil ausgestattet mit dem Minarett-Turm. Diese Erscheinungen bedeuten die Erfüllung der grundgesetzlichen Forderung der Gewissens- und Religionsfreiheit.

Die Präsenz des Islams in der Kultur der Abendlandes bedeutet keineswegs Präsenz einer abstrakten Größe, sondern Präsenz konkreter Menschen, deren Religion Islam ist ${ }^{40}$. Darüber hinaus sind präsent und lebendig in Europa auch solche Vorstellungen von den Islam-Gläubigen, die keiner Realität entsprechen. Zum Beispiel das Familienleben in Islam ist einem breiteren Publikum kaum bekannt ${ }^{41}$. Für den modernen christlich-muslimischen Dialog ist das Bild von Islam als einer antiken, vormittelalterlichen und grundsätzlich unveränderlichen Religion, von Bedeutung. Kaum jemand, ausgenommen manche Wissenschaftler und Forscher auf diesem Gebiet, ist sich dessen bewusst, wie verschieden das Verhältnis der Islam-Gläubigen zu ihrer Religion sein kann. Der durchschnittliche Konsument der medialen Breies realisiert Islam vor allem im Rahmen der Medien-Kampagnen, die meistens politisch gefärbt sind und Stark vereinfachte, religiös bestimmte Elemente des Islam darstellen, wie z.B. Kleidungsregeln (Kopftuch) oder Essbräuche (das halal-Fleisch) oder das Fasten im Monat ramadan ${ }^{42}$.

Der christlich-islamische Dialog hat eigene theologische Grundfragen. $\mathrm{Zu}$ ihnen gehören vor allem das Gottesbild, religiöse Ethik sowie religiöse Autorität ${ }^{43}$. Staat und Gesellschaft haben bestimmte Erwartungen den religi-

${ }^{39}$ Vgl. M. Rohe, Der Islam - Alltagskonflikte und Lösungen. Rechtliche Perspektiven, 2. Aufl., Freiburg/Breisgau 2001.

${ }^{40}$ Vgl. M. Rohe, Islamismus in Deutschland. Einige Anmerkungen zum Thema, in: Islamverherrlichung - Wenn Kritik zum Tabu wird, T.G. Schneiders (Hg.), Wiesbaden 2010, S. 171-184.

${ }^{41}$ Vgl. A.M. Piwko, Malżeństwo i rodzina w islamie sunnickim, Warszawa 2016.

${ }^{42}$ Vgl. M. Rohe, Das islamische Recht: Geschichte und Gegenwart, 1. und 2. durchgeseh. Aufl., München 2009; 3. überarb. und erweit. Aufl. 2011.

${ }^{43}$ Vgl. P. Antes, Theologische Grundfragen im christlich-islamischen Dialog. Gottesbild religiöse Ethik - religiöse Autorität, in: Wandel durch Dialog. Gesellschaftliche, politische und theologische Aspekte des Dialogs zwischen Islam und Christentum, H. Engin, M. Reder (Hg.), Stuttgart 2014, S. 51-61. 
ösen Gemeinschaften gegenüber. In Deutschland bedeutet es, dass die christlichen Kirchen die Moslem als Gläubige betrachten, und Islam ist dort etwas bedeutend mehr als nur ein Problem, das mit den Gastarbeitern zu tun hat ${ }^{44}$. Das betrifft z.B. das Gottesbild. Es ist spezifisch für jede Religion, besonders für eine monotheistische Religion, in der es zu den Glaubensgrundwahrheiten gehört. Das Bild Gottes begründet nämlich das ethische Handeln im Alltag, dient als Bezugspunkt sowohl für den Einzelnen wie auch für die Gruppe, indem es religiöse Ethik gestaltet. Diese wird aber nie fertig, sondern entwickelt sich stets, auch im Islam, unter konkreten, historischen Lebensbedingungen ${ }^{45}$. Z.B. die krisenerfahrene Arbeitsethik sowie die Ethik des Wirtschaftslebens liefern immer neue Fragen. Eine Antwort darauf kann nur eine monotheistische Religion erteilen. Eine wichtige ethische Frage ist die Frage nach einer Autorität. Im christlich-islamischen Dialog können Lösungsmodelle skizziert und gefunden werden, da auch im Bereich des Protestantismus eine Lösungspalette breiter ist als nur eine Berufung auf die staatsrechtlich bestimmte Landeskirchen ${ }^{46}$.

An den Dialog ist die Hoffnung zu knüpfen, dass er eine verändernde Macht hat - und zwar auf den beiden Seiten, die an einem Gesprächstisch Platz nehmen ${ }^{47}$. Wichtig ist, die eigene Identität dabei nicht zu vergessen. Der Papst Benedykt XVI hat mehrmals das Christentum gemahnt und daran erinnert, dass es ein Dialogpartner auch für Moslem sein kann, jedoch nur, wenn es sich der eigenen Identität bewusst ist und seinen Gottesglauben mit all seinen Konsequenzen für das menschliche Leben aufs Neue entdeckt ${ }^{48}$. Der interreligiöse Dialog kann nur auf dem Boden der Freiheit geführt werden. Nur auf diese Art und Weise kann eine Annäherung verschiedener Religionen geschehen. Der Dialog entspringt nämlich der Überzeugung, Religion und Glauben haben mit der Vernunft zu tun, und sie sind fähig, die Wahrheit zu finden ${ }^{49}$.

${ }^{44}$ Vgl. C. Bizer, Flurgespräche in einer traditionsreicher Theologischen Fakultät, in: Religion und Wahrheit. Religionsgeschichtliche Studien. Festschrift für Gernot Wießner zum 65. Geburtstag, B. Köhler (Hg.), Wiesbaden 1998, S. 329-338.

${ }^{45}$ Vgl. H. Obeidat, Wprowadzenie do dialogu muzutmańsko-chrześcijańskiego w celu zapewnienia dialogu opartego na naukach islamu i chrześcijaństwa, in: Dialog chrześcijańsko-muzulmański, t. 3: Teoria - praktyka-perspektywy, M. Lewicka, C. Łapisz (Hg.), S. 41-58.

${ }^{46}$ Vgl. P. Antes, Theologische Grundfragen im christlich-islamischen Dialog. Gottesbildreligiöse Ethik - religiöse Autorität, S. 54.

${ }^{47}$ Vgl. H.-J. Jaschke, Dialog verändert - Religionen im Gespräch, in: Wandel durch Dialog. Gesellschaftliche, politische und theologische Aspekte des Dialogs zwischen Islam und Christentum, H. Engin, M. Reder (Hg.), S. 57-61.

${ }^{48}$ Vgl. ebd., S. 57.

49 Moderne deutschsprachige Theologie, darunter vor allem Fundamentaltheologie (Apologetik), werden nicht müde, die Rationalität der Glaubensverantwortung zu betonen, z.B.: C. Böttigheimer, Lehrbuch der Fundamentaltheologie. Die Rationalität der Gottes-, Offenbarungsund Kirchenfrage, S. 85-114; M. Knapp, Die Vernunft des Glaubens. Eine Einführung in die 
Aus diesem Grund Dialog und Sendung schließen sich nie aus, sondern sich gegenseitig ergänzen und unterstützten.

Christlich-islamischer Dialog trifft auf seinem Wege nicht wenige Schwierigkeiten ${ }^{50}$. Eine von ihnen ist die radikale Islam-Kritik und damit verbundener Moslem-Hass ${ }^{51}$. Der 11. September 2011 bildet hier ein Grenzdatum. Seitdem nehmen spürbar die Ängste vor dem ,radikalen Islam” $\mathrm{zu}^{52}$. Viele bedeutende Intellektuelle skizzieren - mit manchen Vereinfachungen - eine apokalyptische Vision der Einverleibung der westlichen Zivilisation und Kultur durch die parallele Gesellschaft des Islams. Die Botschaft von einer „Islamisierung von Europa" hat sich in unserem Kontinent verbreitet. In Deutschland - in einem Land, das eine bestimmte Erfahrung mit dem Islam gemacht hat - werden immer mehr und immer lauter Stimmen, dass das Land sich auf einem direkten Wege zur Selbstvernichtung befindet: „Deutschland schafft sich $a b " 53$. Die Strategie eines feindlichen Diskurses über Islam will ihn als eine religiöse, kulturelle, und vor allem politische Größe zeigen, derer typisches Merkmal der islamische Terror sein muss ${ }^{54}$. Für diesen Zweck kann man zur Genüge die Traditionen im Wahrnehmen des Islams instrumentalisieren ${ }^{55}$.

Die Integration der Moslems wird zu einer genauso dringenden wie auch schwierigen Aufgabe für das ganze Abendland ${ }^{56}$. Und das zu Zeiten, in denen die Aussage von Oriana Fallaci, die den Islam als solchen mit dem islamischen Terrorismus identifiziert, von vielen unkritisch als eine eigene Meinung angenommen wird ${ }^{57}$. Im Diskurs zum Thema „Islam” - der zwar notwendig ist, der aber mit einer profunden Sachkenntnis und Argumenten statt Verleumdungen, und vor allem auf der Augenhöhe - zwischen Moslems und NichtMoslems geführt werden soll - werden Ängste, verursacht durch den Zustrom der Fremden, artikuliert, Kultur- und Rassenwiderwille belebt, und religiöse

Fundamentaltheologie, Freiburg-Basel-Wien 2009, S. 131-157; K. Wenzel, Offenbarung - Text Subjekt. Grundlegungen der Fundamentaltheologie, Freiburg-Basel-Wien 2016, S. 13-44.

${ }^{50}$ Vgl. E. Sakowicz, Dialog chrześcijaństwa z islamem w nauczaniu Jana Pawła II, in: Dialog międzyreligijny. H. Zimoń (Hg.), Lublin 2004, S. 259-288.

${ }^{51}$ Vgl. W. Benz, Radikale Kritik am Islam. Ursachen und Motive der Muslimfeindschaft, in: Wandel durch Dialog. Gesellschaftliche, politische und theologische Aspekte des Dialogs zwischen Islam und Christentum, H. Engin, M. Reder (Hg.), S. 65-71.

${ }^{52} \mathrm{Vgl}$. W. Benz, Die Feinde aus dem Morgenland. Wie die Angst vor den Muslimen unsere Demokratie gefährdet, München 2012.

${ }^{53} \mathrm{Vgl}$. T. Sarrazin, Deutschland schafft sich ab. Wie wir unser Land aufs Spiel setzen, München 2010.

54 Vgl. W. Pfüller, Interreligiöse Perspektiven. Studien zur Religionstheologie und zur Komparativen Theologie, Berlin-Münster 2012, S. 175-185.

${ }^{55}$ Vgl. W. Benz, Radikale Kritik am Islam. Ursachen und Motive der Muslimfeindschaft, S. 66.

56 Vgl. Religion und Gemeinschaft. Die Frage nach der Integration aus christlicher und muslimischer Perspektive, M. Rothgangel, E. Aslan, M. Jäggle (Hg.), Göttingen 2013.

${ }^{57}$ Vgl. O. Fallaci, Die Wut und der Stolz, München 2004. 
Animositäten instrumentalisiert. Der gesellschaftliche Friede ist mehr als notwendig. Noch wichtiger scheint aber die Bereitschaft zu einem Dialog zu sein sowie der Wille, voneinander zu lernen, sich gegenseitig zu verstehen und zu tolerieren ${ }^{58}$. All diese Probleme soll man in ihrer Ganzheit, ohne irgendwelche Schmälerung oder Retusche in den christlich-islamischen Dialog übertragen ${ }^{59}$. Der zunehmenden Konfrontationsatmosphäre ist nämlich eine entschiedene Kultur des Verständnisses gegenüberzustellen ${ }^{60}$. Es ist das Gebot der Stunde, zur Zeit einer tiefen Migrationskrise in Europa ${ }^{61}$.

In dieser Situation, unter diesen Bedingungen, schlägt Henning Wrogemann (*1964), Inhaber des Lehrstuhls für Missionswissenschaft, Religionswissenschaft und Ökumenik an der Kirchlichen Hochschule Wuppertal/Bethel, einen neuen Weg: die bisherige Theologie der Religionen in die Theologie Interreligiöser Beziehungen umzumodeln ${ }^{62}$. Er zieht eine kritische Bilanz der bisherigen Resultate der wissenschaftlichen Forschung auf dem Gebiet der Theologie der Religionen, betrieben von den verschiedenen christlichen Theologen ${ }^{63}$. Auf der Basis einer vertieften und vielseitigen Reflexion, in der er auch die Vertreter einer pluralistischen Religionstheologie (John Hick, Paul Knitter) berücksichtigt ${ }^{64}$, kommt er zu einem Schluss, eine Theorie Interreligiöser Beziehungen aufzubauen, die sich von einer Theologie Interreligiöser Beziehungen unterscheidet. Bausteine dieser Theorie Interreligiöser Beziehungen sind die folgenden: sie basiert auf einem identitätsorientierten Austauschkonzept zwischen den Religionen, ist eine Wahrnehmungslehre, ein interdisziplinäres Projekt, ein Lernfeld und eine Inspiration, aber auch ein Korrektiv ${ }^{65}$. Dieses Projekt scheint wertvoll zu sein, weil es aus dem Bisherigen Konsequenzen zieht und einen neuen Weg im interreligiösen Dialog zu bahnen vermag ${ }^{66}$. So verdient es ein weiteres Studium.

${ }^{58}$ Vgl. W. Benz, Radikale Kritik am Islam. Ursachen und Motive der Muslimfeindschaft, S. 71.

${ }^{59} \mathrm{Vgl}$. A. Paluszek, Dialog chrześcijańsko-muzutmański a polityka integracyjna w Niemczech, in: Dialog chrześcijańsko-muzutmański, t. 3: Teoria-praktyka-perspektywy, M. Lewicka, C. Łapisz (Hg.), S. 171-194.

${ }^{60}$ Vgl. K. Gabriel, Religion in Zeiten der Globalisierung: Wachsende Konfrontation und ihre Überwindung durch eine Kultur der Verständigung, in: Wandel durch Dialog. Gesellschaftliche, politische und theologische Aspekte des Dialogs zwischen Islam und Christentum, H. Engin, M. Reder (Hg.), S. 72-81; T. Specker, Im Gegenüber - Skizze zu einer ,,Katholischen Theologie im Angesicht des Islam", in: Wandel durch Dialog. Gesellschaftliche, politische und theologische Aspekte des Dialogs zwischen Islam und Christentum, H. Engin, M. Reder (Hg.), S. 173-187.

${ }^{61} \mathrm{Vgl}$. Religion im Wandel. Transformation religiöser Gemeinschaften in Europa durch Migration - Interdisziplinäre Perspektiven, R. Polak, W. Reiss (Hg.), Göttingen 2015.

${ }^{62}$ Vgl. H. Wrogemann, Theologie Interreligiöser Beziehungen. Religionstheologische Denkwege, kulturwissenschaftliche Anfragen und ein methodischer Neuansatz, Gütersloh 2015, S. 21-42.

${ }^{63}$ Vgl. ebd., S. 43-68.

${ }^{64}$ Vgl. ebd., S. 69-209.

${ }^{65}$ Vgl. ebd., S. 211-223.

${ }^{66} \mathrm{Vgl}$. R. Göllner, Interreligiöses Lernen: Überforderung oder Chance für den Religionsunterricht?, in: Das Christentum und die Weltreligionen, R. Göllner (Hg.), Münster 2000, S. 145-169. 


\section{Schluss}

Der praktische Auslöser für das Thema dieser Abhandlung ist vor allem die aktuelle Migrationskrise in Europa gewesen. Dieser Umstand wirft gewichtige Fragen nicht nur für Politik und Wirtschaft auf, sondern auch für die Kirche und ihre Theologie. Es hat sich gezeigt, dass nicht die praktische Lösungsvorschläge des Problems im Vordergrund stehen sollen, sondern eine gute, theoretische Reflexion, die die Grundlagen der christlichen Religion berücksichtigt. Darunter geht es um ihr Verhältnis zu den anderen Weltreligionen. Die heutige Theologie, insbesondere die Fundamentaltheologie in deutschem und polnischen Sprachraum betont die Bedeutung der Wahrheitsfrage im Kontext der Offenbarung Gottes. Die Offenbarung ist nach wie vor das Prinzip der gesamten Theologie und der Bestimmung ihres Verhältnisses zu den nichtchristlichen Religionen. Erst auf diesem Fundament kann man einige Richtlinien für den christlich-islamischen Dialog ausarbeiten. Als besonders wertvoll zeigt sich in der Theologie der Religionen das neue Konzept von Henning Wrogemann, der einen Übergang von der Theologie der Religionen zur Theologie Interreligiöser Beziehungen fordert. Seine Theorie Interreligiöser Beziehungen bildet eine praktische Umsetzung des interreligiösen Dialogs, der auf allen Seiten neue Kompetenzen braucht.

\section{THE IMPORTANCE AND THE ROLE OF GOD`S REVELATION IN THE INTERRELIGIOUS DIALOGUE}

\section{Summary}

The current migration crisis in Europe is a practical context of this study. A lot of refugees, predominantly Muslims, are constantly coming to our continent. This fact raises important questions and challenges not only to politics and economy, but also to the Church and its theology. It has already occurred many times that one should focus not only on finding practical solutions to the problem, but also a deeper, honest theoretical reflection that takes into account the foundations of Christian doctrine. In this case, it is mainly about the relationship of Christianity to other religions. Contemporary theology, especially fundamental theology practiced in the Polish and German linguistic areas, underlines the importance of the question about the truth in the context of God's revelation, its meaning in the context of the relationship of Christianity to other religions and other religions among themselves. God's revelation is the source and principle of all theology, including the criterion of reference of Christianity to non-Christian religions. Practical principles of dialogue between Christianity and Islam can be developed on such a foundation. The new concept by the German theolo- 
gian Henning Enogemann, demanding the transition from theology of religion to theology of interreligious relations turns out to be particularly interesting for theology of religion. His theory of interreligious relations is a practical application of theoretical findings. Interreligious dialogue calls for new competences from all its participants.

Słowa kluczowe: Objawienie; chrześcijaństwo; religie pozachrześcijańskie; islam; dialog międzyreligijny

Keywords: Revelation; Christianity; non-Christian religions; Islam; interreligious dialogue

\section{BIBLIOGRAPHIE}

Antes P., Theologische Grundfragen im christlich-islamischen Dialog. Gottesbild-religiöse Ethikreligiöse Autorität, in: Wandel durch Dialog. Gesellschaftliche, politische und theologische Aspekte des Dialogs zwischen Islam und Christentum, H. Engin, M. Reder (Hg.), Verlag W. Kohlhammer, Stuttgart 2014, S. 51-61.

Benz W., Die Feinde aus dem Morgenland. Wie die Angst vor den Muslimen unsere Demokratie gefährdet, C.H. Beck Verlag, München 2012.

Benz W., Radikale Kritik am Islam. Ursachen und Motive der Muslimfeindschaft, in: Wandel durch Dialog. Gesellschaftliche, politische und theologische Aspekte des Dialogs zwischen Islam und Christentum, H. Engin, M. Reder (Hg.), Verlag W. Kohlhammer, Stuttgart 2014, S. 65-71.

Bizer C., Flurgespräche in einer traditionsreicher Theologischen Fakultät, in: Religion und Wahrheit. Religionsgeschichtliche Studien. Festschrift für Gernot Wießner zum 65. Geburtstag, B. Köhler (Hg.), Harrassowitz Verlag, Wiesbaden 1998, S. 329-338.

Böttigheimer C., Lehrbuch der Fundamentaltheologie. Die Rationalität der Gottes-, Offenbarungsund Kirchenfrage, Verlag Herder, Freiburg-Basel-Wien 2009.

Dziewulski G., Objawienie jako kryterium określenia relacji chrześcijaństwa do religii, „Łódzkie Studia Teologiczne" 15 (2006) S. 41-57.

Dziewulski G., Objawienie jako kryterium określenia relacji między religiami, „Seminare” 24 (2007) S. 127-143.

Eicher P., Offenbarung - Prinzip neuzeitlicher Theologie, Kösel-Verlag, München 1977.

Fallaci O., Die Wut und der Stolz, übers. von P. Cobrace, List Verlag, München 2004.

Gabriel K., Religion in Zeiten der Globalisierung: Wachsende Konfrontation und ihre Überwindung durch eine Kultur der Verständigung, in: Wandel durch Dialog. Gesellschaftliche, politische und theologische Aspekte des Dialogs zwischen Islam und Christentum, H. Engin, M. Reder (Hg.), Verlag W. Kohlhammer, Stuttgart 2014, S. 72-81.

Göllner R., Interreligiöses Lernen: Überforderung oder Chance für den Religionsunterricht?, in: Das Christentum und die Weltreligionen, R. Göllner (Hg.), LIT Verlag, Münster 2000, S. 145$-169$.

Höhn H.-J., Postsäkular. Gesellschaft im Umbruch - Religion im Wandel, Verlag Ferdinand Schöningh, Paderborn-München-Wien-Zürich 2007.

Jaschke H.-J., Dialog verändert - Religionen im Gespräch, in: Wandel durch Dialog. Gesellschaftliche, politische und theologische Aspekte des Dialogs zwischen Islam und Christentum, H. Engin, M. Reder (Hg.), Verlag W. Kohlhammer, Stuttgart 2014, S. 57-61.

Jähnichen T., Witte-Karp A., Religion und Offenbarung. Ein Studienbuch zur Einführung in die Systematische Theologie, 2. überarb. Aufl., Verlag Hartmut Spenner, Waltrop 2007. 
Knapp M., Die Vernunft des Glaubens. Eine Einführung in die Fundamentaltheologie, Verlag Heder, Freiburg-Basel-Wien 2009.

Krauss R., Gottes Offenbarung und menschliche Religion. Eine Analyse des Religionsbegriffs in Karl Barths Kirchlicher Dogmatik mit besonderer Berücksichtigung F. D. E. Schleiermachers, The Edwin Mellen Press, Lewiston/Queenston/Lampeter 1992.

Ledwoń I.S., Wyjątkowy charakter chrześcijaństwa, in: Chrześcijaństwo a religie. Dokument Międzynarodowej Komisji Teologicznej. Tekst - Komentarze - Studia, I.S. Ledwoń, K. Pek (Hg.), Wydawnictwo Księży Marianów, Lublin-Warszawa 1999, S. 81-100.

Leuze R., Das Christentum. Grundriss einer monotheistischen Religion, Vandenhoeck \& Ruprecht, Göttingen 2010.

Miggelbrink R., 50 Jahre nach dem Konzil. Die Zukunft der katholischen Kirche, Verlag Ferdinand Schöningh, Paderborn-München-Wien-Zürich 2012.

Obeidat H., Wprowadzenie do dialogu muzułmańsko-chrześcijańskiego w celu zapewnienia dialogu opartego na naukach islamu i chrześcijaństwa, in: Dialog chrześcijańsko-muzulmański, t. 3: Teoria - praktyka - perspektywy, M. Lewicka, C. Łapisz (Hg.), S. 41-58.

Paluszek A., Dialog chrześcijańsko-muzutmański a polityka integracyjna w Niemczech, in: Dialog chrześcijańsko-muzulmański, t. 3: Teoria - praktyka - perspektywy, M. Lewicka, C. Łapisz (Hg.), Wydawnictwo Naukowe Uniwersytetu Mikołaja Kopernika, Toruń 2013, S. 171-194.

Pannenberg W. (Hg.), in Verbindung mit R. Rendtorff, U. Wilckens, T. Rendtorff, Offenbarung als Geschichte, Vandenhoeck \& Ruprecht, Göttingen 1982.

Pękala U., Eine Offenbarung - viele Religionen. Die Vielfalt der Religionen aus christlicher Perspektive auf der Grundlage des Offenbarungsbegriffs Wolfhart Pannenbergs, Echter Verlag, Würzburg 2010.

Pfüller W., Interreligiöse Perspektiven. Studien zur Religionstheologie und zur Komparativen Theologie, LIT Verlag, Berlin-Münster 2012

Piwko A.M., Matżeństwo i rodzina w islamie sunnickim, Instytut Dialogu Kultury i Religii Uniwersytetu Kardynała Stefana Wyszyńskiego, Warszawa 2016.

Rahner K., Grundkurs des Glaubens. Einführung in den Begriff des Christentums, Verlag Herder, Freiburg-Basel-Wien 1984.

Religion im Wandel. Transformation religiöser Gemeinschaften in Europa durch Migration - Interdisziplinäre Perspektiven, R. Polak, W. Reiss (Hg.), Vienna University Press, Göttingen 2015.

Religion und Gemeinschaft. Die Frage nach der Integration aus christlicher und muslimischer Perspektive, M. Rothgangel, E. Aslan, M. Jäggle (Hg.), Vienna University Press, Göttingen 2013.

Rohe M., Der Islam - Alltagskonflikte und Lösungen. Rechtliche Perspektiven, 2. Aufl., Verlag Herder, Freiburg/Breisgau 2001.

Rohe M., Das islamische Recht: Geschichte und Gegenwart, 1. und 2. durchgeseh. Aufl., Verlag C.H. Beck, München 2009; 3. überarb. und erweit. Aufl. 2011

Rohe M., Islamismus in Deutschland. Einige Anmerkungen zum Thema, in: Islamverherrlichung Wenn Kritik zum Tabu wird, T.G. Schneiders (Hg.), Vs Verlag für Sozialwissenschaften, Wiesbaden 2010, S. 171-184.

Rohe M., Zum Wandel der deutschen und europäischen Gesellschaften durch die Präsenz des Islam, in: Wandel durch Dialog. Gesellschaftliche, politische und theologische Aspekte des Dialogs zwischen Islam und Christentum, H. Engin, M. Reder (Hg.), Verlag W. Kohlhammer, Stuttgart 2014, S. 14-19.

Rusecki M., Elementy zbawcze w religiach pozachrześcijańskich, in: Odkupienie a dialog międzyreligijny. Materiaty z sympozjum w Obrze 20-21 kwietnia 1999 roku, W. Kluj (Hg.), Wydział Teologiczny UAM, Poznań 1999, S. 41-48.

Rusecki M., Elementy zbawcze w religiach pozachrześcijańskich, in: Religia w świecie wspótczesnym, H. Zimoń (Hg.), TN KUL, Lublin 2001, S. 531-562.

Rusecki M., Objawienie Boże podstawa religii, in: Teologia religii. Chrześcijański punkt widzenia, G. Dziewulski (Hg.), Wydawnictwo Księży Sercanów, Łódź-Kraków 2007, S. 157-182. 
Sakowicz E., Dialog chrześcijaństwa z islamem w nauczaniu Jana Pawła II, in: Dialog międzyreligijny. H. Zimoń (Hg.), TN KUL, Lublin 2004, S. 259-288.

Sakowicz E., Rozwiązywanie konfliktów i budowanie jedności. Pedagogiczna propozycja M. Fethullaha Gülena, in: Dialog chrześcijańsko-muzulmański, t. 3: Teoria - praktyka - perspektywy, M. Lewicka, C. Łapisz (Hg.), Wydawnictwo Naukowe Uniwersytetu Mikołaja Kopernika, Toruń 2013, S. 107-124.

Sarrazin T., Deutschland schafft sich ab. Wie wir unser Land aufs Spiel setzen, Deutsche VerlagsAnstalt (DVA), München 2010.

Scheffczyk L., Absolutny charakter chrześcijaństwa, in: Tajemnica odkupienia, L. Balter u.a. (Hg.), Pallottinum, Poznań 1997, S. 477-490.

Senn F., Verantwortet glauben. Fundamentaltheologie, Theologischer Verlag Zürich, Zürich 2016.

Specker T., Im Gegenüber - Skizze zu einer „Katholischen Theologie im Angesicht des Islam”, in: Wandel durch Dialog. Gesellschaftliche, politische und theologische Aspekte des Dialogs zwischen Islam und Christentum, H. Engin, M. Reder (Hg.), Verlag W. Kohlhammer, Stuttgart 2014, S. 173-187.

Sung Ryul Kim, Gott in und über den Religionen. Auseinandersetzung mit der ,,pluralistischen Religionstheologie" und das Problem des Synkretismus, Theologischer Verlag Zürich, Zürich 2010.

Universale Offenbarung? Der eine Gott und die vielen Religionen, W. Zager (Hg.), Evangelische Verlagsanstalt Leipzig, Leipzig 2013.

Waldenfels H., Christus und die Religionen, Topos Plus Verlagsgemeinschaft, Regensburg 2002.

Waldenfels H., Chrystus a religie, übers. von B. Drąg, Wydawnictwo WAM, Kraków 2004.

Ward K., Religion and Revelation. A Theology of Revelation in the World's Religions, Clarendon Press, Oxford 1994.

Wenzel K., Offenbarung - Text - Subjekt. Grundlegungen der Fundamentaltheologie, Verlag Herder, Freiburg-Basel-Wien 2016.

Wiedenhofer S., Offenbarung, in: Neues Handbuch theologischer Grundbegriffe, erw. Neuausgabe, P. Eicher (Hrsg.), Bd. IV, Kösel-Verlag, München 1991, S. 98.

Wrogemann H., Theologie Interreligiöser Beziehungen. Religionstheologische Denkwege, kulturwissenschaftliche Anfragen und ein methodischer Neuansatz, Gütersloher Verlagshaus, Gütersloh 2015.

Żmudziński M., Wyjątkowy charakter Objawienia chrześcijańskiego w kontekście pluralizmu religijnego, „Studia Elbląskie” XI (2010) S. 113-122.

IGNACY BoKWA, kapłan diecezji radomskiej (1982), doktor habilitowany nauk teologicznych w zakresie teologii dogmatycznej (1998), profesor tytularny nauk teologicznych (2011), profesor zwyczajny na Wydziale Teologicznym UKSW w Warszawie (2012), kierownik Katedry Dialogu Kultury Artystycznej i Teologii (2017). Członek Societas Oecumenica i Görres-Gesellschaft oraz Towarzystwa Teologów Dogmatyków (TTD), prezes TTD na kadencję 2014-17. Stały współpracownik Redakcji Katolickiej Polskiego Radia (od 1992). Pola badań: teologia dogmatyczna, teologia kultury, teologia religii. W latach 1999-2012 członek Senatu UKSW. Ekspert Narodowego Centrum Nauki. Członek redakcji „Studia Theologica Varsaviensia" (od 1994). Członek Komisji ds. Nagród Ministerstwa Nauki i Szkolnictwa Wyższego (2015). Ostatnio opublikował: Teologia w warunkach nowoczesności i ponowoczesności (2010), I. Bokwa, M. Jagodziński (red.), Wobec nowego ateizmu (2011), I. Bokwa, M. Jagodziński (red.), Wiara wobec wspótczesności, Warszawa 2014. 